06

\title{
Влияние науглероживания вольфрама на активацию газа при синтезе алмазных структур
}

\author{
(C) А.А. Емельянов, М.Ю. Плотников, И.Б. Юдин \\ Институт теплофизики им. С.С. Кутателадзе СО РАН, \\ 630090 Новосибирск, Россия \\ e-mail: plotnikov@itp.nsc.ru
}

Поступило в Редакцию 22 марта 2018 г.

В окончательной редакции 17 апреля 2019 г.

Принято к публикации 7 июня 2019 г.

С целью развития газоструйного метода осаждения алмазных структур исследовано течение смеси водорода с метаном через коаксиальные нагретые вольфрамовые цилиндрические каналы со встроенной в них вольфрамовой спиралью. Основное внимание уделено исследованию науглероживания вольфрамовых поверхностей при газоструйном осаждении и влиянию науглероживания на скорость осаждения и морфологию осаждаемых покрытий. Проведена серия экспериментов по исследованию науглероживания вольфрамовых поверхностей при разных условиях подачи смеси водорода и метана. Проведено прямое статистическое моделирование течения смеси. Определены возможные пути попадания метана и его фрагментов на поверхность спирали.

Ключевые слова: газоструйный метод, алмаз, науглероживание вольфрама.

DOI: $10.21883 / J T F .2019 .12 .48488 .127-18$

\section{Введение}

Метод газофазного осаждения с использованием термической активации (Hot-Wire Chemical Vapor Deposition (HWCVD)) газов-предшественников широко применяется для синтеза алмазных структур [1-4]. Этот метод основан на использовании смесей водорода и углеродсодержащих газов, активированных на горячих металлических поверхностях и взаимодействующих с относительно холодной поверхностью подложки. Процесс осаждения алмазоподобных структур газофазным методом представляет собой многопараметрическую задачу [1-4]. При заданных условиях на подложке он определяется соотношением концентраций сталкивающихся с поверхностью подложки атомарного водорода и фрагментов развала исходных углеродсодержащих газов (в нашем случае - метана).

В настоящей работе рассматривается газоструйная модификация этого метода, заключающаяся в активации смеси водорода с метаном при взаимодействии с горячими вольфрамовыми поверхностями цилиндрических каналов и спирали [5-11]. При таком подходе многократные столкновения молекул с поверхностями обеспечивают более высокую степень диссоциации водорода $[10,12,13]$. Другой отличительной особенностью этого подхода по сравнению с классическим методом HWCVD, где активные компоненты транспортируются к подложке диффузией, является использование высокоскоростной струи для доставки активных компонентов к подложке, что обеспечивает повышенную скорость доставки и возможность их „заморозки“.

Вольфрам широко используется при осаждении алмазоподобных структур из смесей углеродсодержащих газов с водородом как в качестве нагревательного элемента, так и в качестве катализатора для диссоциации водорода. Одна из проблем, которую приходится решать при термической активации, является науглероживание вольфрама при взаимодействии с углеродсодержащими газами, что существенно влияет как на электрические, так и на каталитические свойства вольфрама [14-18].

В настоящей работе численно и экспериментально исследуется науглероживание вольфрамовой поверхности спирали при газоструйном осаждении, а также влияние науглероживания на скорость осаждения и морфологию алмазных структур.

\section{Методика эксперимента}

На рис. 1 представлена схема реактора для активации и транспортировки газов к подложке. Реактор расположен в вакуумной камере объемом около $0.5 \mathrm{~m}^{3}$. Кольцевой канал 1 диаметром $13 \mathrm{~mm}$ и трубка 5 диаметром $3 \mathrm{~mm}$ выполнены из двуслойной вольфрамовой фольги толщиной $30 \mu \mathrm{m}$. Внутри канала 1 коаксиально расположена цилиндрическая спираль 2 и трубка 5. Спираль выполнена из вольфрамовой проволочки диаметром $1 \mathrm{~mm}$. Она имеет пять витков в горячей зоне с диаметром намотки $8 \mathrm{~mm}$. Тепловой экран 6 диаметром $17 \mathrm{~mm}$ выполнен из двуслойной молибденовой фольги толщиной $50 \mu \mathrm{m}$. Длина горячей части реактора составляла $22 \mathrm{~mm}$, расстояние до подложки - $10 \mathrm{~mm}$. Подложка 3 диаметром $20 \mathrm{~mm}$ выполнена из молибденовой фольги толщиной $250 \mu \mathrm{m}$. Перед началом эксперимента камера откачивалась до давления $26.7 \mathrm{~Pa}$, а затем во время эксперимента давление поддерживалось на уровне 2666 Ра. В трубку 5 подавалась смесь $\mathrm{H}_{2}+\mathrm{CH}_{4}$, в 


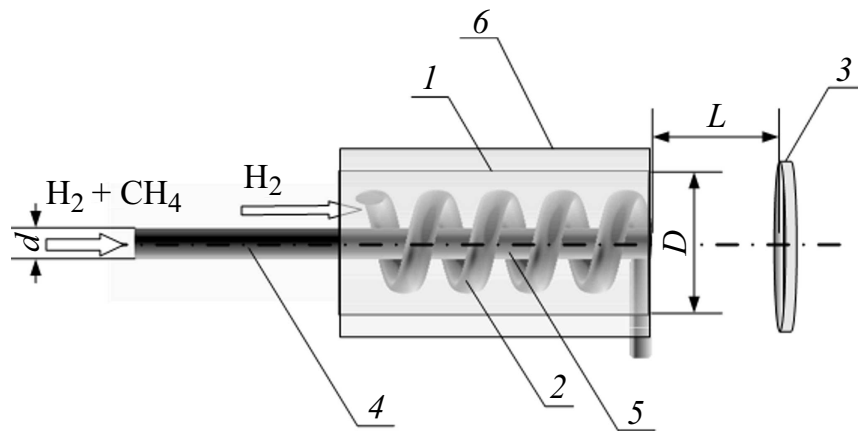

Рис. 1. Схема транспортировки газов к подложке: 1 - кольцевой канал, 2 - вольфрамовая спираль, 3 - молибденовая подложка, 4 - трубка для подачи смеси $\mathrm{H}_{2}+\mathrm{CH}_{4}, 5-$ горячая часть трубки, 6 - тепловой экран.

кольцевой канал - только водород (1500 sccm). Расход водорода, подаваемого через трубку 1 , также составлял $1500 \mathrm{sccm}$, а расход метана в смеси варьировался от 2 до $16 \mathrm{sccm}$.

Температуры трубок 1,4 и 6 измерялись с помощью вольфрам-рениевых термопар с диаметром электродов $100 \mu \mathrm{m}$ и молибденовой подложки 3 с помощью хромель-алюмелевой термопары с диаметром электродов $200 \mu \mathrm{m}$. Королек термопар закладывался в стенках каждой трубки между слоями фольги. Температура спирали оценивалась по методике [19]. Температура поверхности кольцевого канала во время экспериментов была около $2100 \mathrm{~K}$. Перед началом эксперимента подбиралась мощность, обеспечивающая при подаче заданного расхода водорода температуру $2400 \mathrm{~K}$ для трубки 1 . Эта мощность использовалась в ходе эксперимента по осаждению алмазных структур. В этих условиях температура спирали оценочно имела значение около $2500 \mathrm{~K}$. Подложка нагревалась тепловым потоком от реактора, ее температура регистрировалась термопарой, приваренной к подложке с тыльной стороны. В ходе эксперимента измерялись сила тока и напряжение на спирали. Стандартное время осаждения составляло $3 \mathrm{~h}$.

\section{Науглероживание вольфрама и его влияние на процесс осаждения алмазных структур методом HWCVD}

Атомарный водород играет одну из ключевых ролей в газофазном осаждении алмазных структур. Он необходим для строительства алмазной решетки на поверхности подложки. Исследования показали незначительный вклад в разложение метана гетерогенных реакций $[3,20]$, поэтому вторая важная функция атомарного водорода - участие в разложении в газовой фазе метана на фрагменты.

Диссоциация молекулярного водорода на чистой поверхности вольфрама начинается при температуре поверхности $>1600 \mathrm{~K}$ и ее скорость увеличивается с ростом температуры [21]. Ограничением сверху по температуре при использовании HWCVD для осаждения алмаза является начало активного испарения вольфрама. При взаимодействии вольфрама с углеродсодержащими газами происходит его науглероживание, что приводит к росту электросопротивления и снижению каталитической активности. Все это влияет на стабильность проведения эксперимента и скорость осаждения. Поэтому большое внимание было уделено изучению науглероживания вольфрама применительно к использованию HWCVD для осаждения алмаза [14-18]. Исследователи использовали разные методики с разной точностью. Поэтому частично выводы не совпадают.

Процесс науглероживания вольфрама включает в себя два основных тесно взаимосвязанных процесса: образование углерода на поверхности металла вследствие разложения газа и диффузию атомов углерода вовнутрь с образованием карбидных форм $\mathrm{W}_{2} \mathrm{C}$ и $\mathrm{WC}$ и твердого раствора. В работе [14] исследованы кинетика и механизм взаимодействия вольфрама с метаном в области температур $1573-2823 \mathrm{~K}$ и давлений метана 266-8000 Ра. При этом могут реализовываться два качественно различных режима роста диффузионных слоев - кинетический и диффузионный [14]. С помощью металлографического и рентгенофазового анализов на первой стадии обнаружена только одна карбидная фаза $\mathrm{W}_{2} \mathrm{C}$. На второй стадии диффузионная зона становится двуслойной (наряду с $\mathrm{W}_{2} \mathrm{C}$ появляется фаза $\mathrm{WC}$ ), и в дальнейшем происходит рост обоих карбидных слоев. Толщина внешнего слоя WC всегда значительно меньше толщины внутреннего слоя $\mathrm{W}_{2} \mathrm{C}$. Установлено, что при давлении $1333 \mathrm{~Pa}$ во всем исследуемом диапазоне температур образование свободного углерода на поверхности не наблюдалось. Хроматографическим анализом установлено постоянство состава газообразных продуктов пиролиза - в основном это водород, а при $T>2273 \mathrm{~K}$ наблюдались следы ацетилена в количестве $<2 \%$ от количества разложения метана. Отмечено увеличение скорости разложения метана с ростом температуры.

В работе [15] изучалась карбидизация вольфрамовых нитей в газовой смеси $\mathrm{CH}_{4}-\mathrm{H}_{2}$ при температуре проволочек $2373 \mathrm{~K}$ в типичных условиях нанесения алмазного напыления. Вольфрамовая нить полностью превращалась в $\mathrm{WC}$ и $\mathrm{W}_{2} \mathrm{C}$ при $2373 \mathrm{~K}$ через $24 \mathrm{~h}$ как при $0.5 \%$, так и при $1.0 \% \mathrm{CH}_{4}$. При уменьшении времени карбидизации до $5 \mathrm{~h}$ внешний слой нити содержал $\mathrm{WC}$ и $\mathrm{W}_{2} \mathrm{C}$, тогда как внутренний сердечник содержал чистый вольфрам. Температура вольфрамовых нитей уменьшалась со временем, вероятно, из-за увеличения диаметра нити во время науглероживания, а также комбинации различных фаз (карбид-субкарбид и металлическая фаза), которые имеют разную электрическую проводимость и разную тепловую эффективность.

В работе [16] показан рост с течением времени сопротивления проволочки из вольфрама, помещенной в атмосферу метана. Этот рост авторы отнесли к последствиям карбидизации проволочки. При температуре $2580 \mathrm{~K}$ ими 
отмечено достаточно медленное и слабое изменение сопротивления (10\% за $6 \mathrm{~h})$. Отмечено, что проволочку можно обезуглероживать без какой-либо заметной потери свойств вольфрама. Это делалось много раз путем нагрева до $2800 \mathrm{~K}$ в вакууме или в потоке водорода при $0.13 \mathrm{~Pa}$. Показано, что смешивание водорода с углеродсодержащим газом заметно увеличивает вероятность разложения метана на поверхности: так, при температуре проволочки $2610 \mathrm{~K}$ она увеличилась с $6.4 \cdot 10^{-3}$ (только метан) до $2.6 \cdot 10^{-2}$ (метан и водород). Этот эффект, возможно, объясняется наличием углеродных пятен на поверхности $\mathrm{W}_{2} \mathrm{C}$. Эти пятна обладают низкой вероятностью разложения метана, но могут удаляться адсорбированным водородом.

В работе [17] проведен комплексный анализ влияния карбидизации проволочек из вольфрама на их свойства. Исследовались степень черноты, электрическое сопротивление, мощность, затрачиваемая на нагрев до заданной температуры, и каталитические свойства поверхности. Проволочки предварительно карбидизировались при $2173 \mathrm{~K}$ в смесях $1 \% \mathrm{CH}_{4} / \mathrm{H}_{2}$ или $0.5 \% \mathrm{C}_{2} \mathrm{H}_{2} / \mathrm{H}_{2}$. Процесс карбидизации контролировался путем измерения сопротивления свернутой в спираль части проволочки. Предполагалось, что карбидизация фактически завершена при достижении устойчивого значения сопротивления. Для вольфрамовых проволочек требуемое время науглероживания составляло около $1 \mathrm{~h}$ и соответствовало увеличению сопротивления на $100 \%$. Эксперименты показали, что при нагреве науглероженных проволочек выше температуры $2423 \mathrm{~K}$ начинается процесс обезуглероживания. Из проведенных экспериментов авторы делают вывод, что переход к травлению углерода водородом на поверхности проволочки происходит при температуре $2473 \mathrm{~K}$ и при $2623 \mathrm{~K}$ поверхность проволочки в основном очищена от углерода. О процессе обезуглероживания можно также судить по данным об уменьшении сопротивления при повышении температуры от 2473 до $2623 \mathrm{~K}$. Изменения при $T=2423 \mathrm{~K}$ также отражаются скачками в величине мощности, необходимой для достижения заданной температуры. Когда поверхность проволочки становится чистой, каталитическая активность проволочки резко возрастает. Об этом свидетельствует ряд косвенных показателей, приведенных в [17]. В частности, в этом случае требуется больше энергии для активации газов-реагентов. Было отмечено резкое увеличение температуры подложки, что может быть обусловлено энергией, высвобождаемой в результате рекомбинации атомов водорода на поверхности подложки. Этот факт служит дополнительным, хотя и косвенным свидетельством повышенной каталитической активности проволочки. Другим косвенным показателем каталитической активности являлось изменение состава окружающего газа.

Наиболее обстоятельное исследование влияния науглероживания вольфрама на его каталитические свойства было проведено авторами [18]. Масс-спектрометрия и рентгеновская фотоэлектронная спектроскопия были использованы для исследования взаимодействия $\mathrm{CH}_{4}$ и $\mathrm{H}_{2}$ с карбидизированными и некарбидизированным вольфрамом. Эксперименты показали значительное испарение $\mathrm{C}, \mathrm{C}_{2}$, и $\mathrm{C}_{3}$ с поверхности карбидизированного вольфрама при температуре выше $2173 \mathrm{~K}$ в вакууме (при этом С больше в 4-5 раз, чем $\mathrm{C}_{2}$ и $\mathrm{C}_{3}$ ). Авторы [18] предполагают, что науглероживание вольфрама в типичном алмазном CVD-реакторе происходит следующим образом. Атомы водорода, десорбированные из горячей вольфрамовой поверхности, в результате реакций в газовой фазе с метаном образуют высокоактивные частицы, такие как метильные радикалы, ацетилен и этилен. Ожидается, что полученные частицы будут намного более реакционноспособными с вольфрамом или науглероженным вольфрамом по сравнению с метаном. По мнению авторов [18], науглероживание вольфрамовых проволочек в CVD-реакторах обусловлено в основном реакцией этих частиц с горячей поверхностью. Ими было обнаружено, что скорость образования атомов водорода из $\mathrm{H}_{2}$ на чистом вольфраме существенно выше, чем на карбидизированном. На графите диссоциация водорода не наблюдалась. В $[17,18]$ представлен большой объем данных, свидетельствующий о том, что вольфрамовая нить в CVD-реакторе науглерожена и химически инертна при температурах ниже $2173 \mathrm{~K}$ и меньше подвержена карбидизации, и более реакционноспособна при температурах выше $2473 \mathrm{~K}$.

\section{Метод прямого статистического моделирования}

Для исследования особенностей течения смеси газов в условиях, близких к экспериментальным, использовался метод прямого статистического моделирования (ПСМ) [22,23]. В основе алгоритма ПСМ лежит моделирование движения частиц и их столкновений между собой и с окружающими поверхностями.

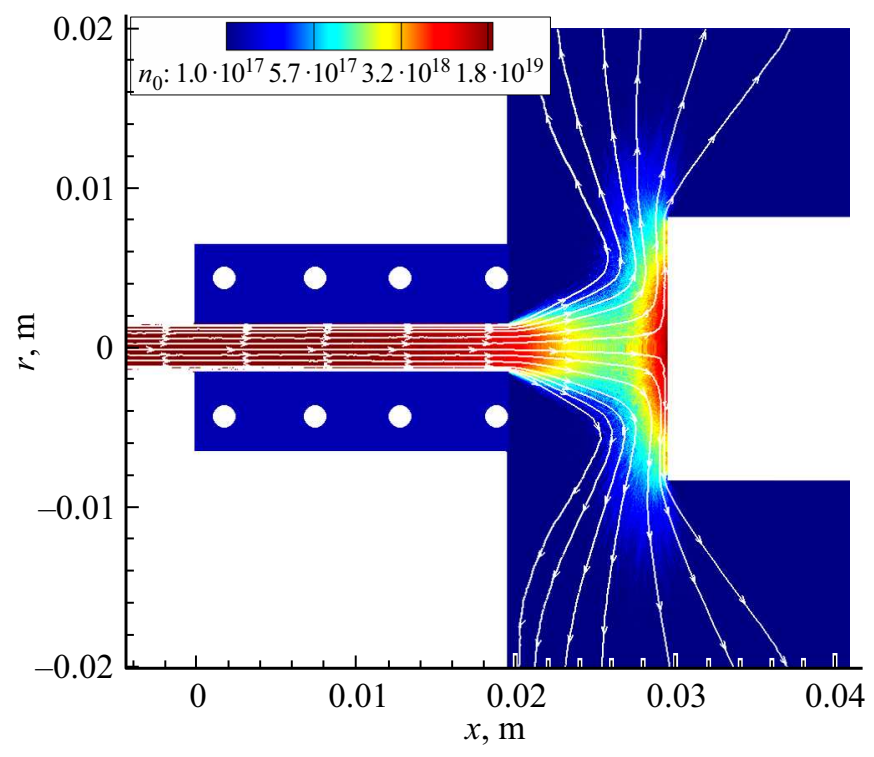

Рис. 2. Расчетная схема - численная плотность и линии тока метана, истекающего из трубки. 
Расчетная схема показана на рис. 2, где приведено пространственное распределение плотности метана. В соответствии со схемой рис. 1 моделировалось течение смеси водорода с метаном через центральную трубку, состоящую из холодного 4 и нагреваемого 5 участков. На выходе из этой трубки течение попадало в спутный поток из кольцевого канала. Температура спирали $-2400 \mathrm{~K}$. При этом горячая часть трубки 5 находилась в тесном лучистом и конвективном контакте со спиралью и также считалась нагретой до температуры $2400 \mathrm{~K}$. В кольцевой канал подавался водород. Внешняя поверхность кольцевого канала имела низкую температуру $(1800 \mathrm{~K})$, поэтому в расчетах для нее принята полная рекомбинация атомарного водорода. Активирующими являются поверхность трубки 5 и спираль. Выбор коэффициентов диссоциации и рекомбинации водорода на трубке 5 и спирали осуществлялся на основе методики [13]. Участие метана в химических реакциях не рассматривалось. Более подробное описание используемых в расчетах параметров метода ПСМ приведено в [24]. Начальная часть трубки имеет „низкую“ температуру $(T=1500 \mathrm{~K})$; для проникающего в эту часть трубки атомарного водорода моделировалась полная рекомбинация на ее поверхности. Эксперименты показали, что внутренняя поверхность центральной трубки покрыта углеродом. Основываясь на результатах $[14,15]$, мы считали внутреннюю поверхность трубки науглероженной и вследствие этого некаталитичной.

\section{Результаты экспериментов и расчетов}

В экспериментах при исследовании степени науглероживания вольфрамовых поверхностей реактора основное внимание было уделено изменению свойств вольфрамовой спирали. Контроль изменения науглероживания спирали осуществлялся измерением ее электрического сопротивления [15-18]. В процессе всего эксперимента измерялось падение напряжения на концах спирали и величина тока в цепи. На рис. 3 представлено изменение относительного электрического сопротивления с течением времени (время измеряется в часах) для различных вариантов подачи смеси при наличии подложки. Результаты получены при следующих параметрах: давление в камере $2666 \mathrm{~Pa}$; температура подложки $1300 \mathrm{~K}$; при совместной подаче расход смеси $\mathrm{H}_{2}+\mathrm{CH}_{4} 1500+15 \mathrm{sccm}$; при раздельной осесимметричной схеме - расход водорода в кольцевом канале $1500 \mathrm{sccm}$ и расход смеси $\mathrm{H}_{2}+\mathrm{CH}_{4}$ в центральном канале $1500+15 \mathrm{sccm}$; при боковой подаче расход водорода в центральном канале $1500 \mathrm{sccm}$ и расход смеси $\mathrm{H}_{2}+\mathrm{CH}_{4}$ через боковую трубку $1500+15 \mathrm{sccm}$.

На первом этапе разработки газоструйного метода осуществлялась совместная подача метана с водородом (отсутствовала центральная трубка 4) [5,6]. Наблюдалось быстрое повышение сопротивления спирали вследствие ее науглероживания (кривая 1). И как результат формирование на поверхности подложки композитного

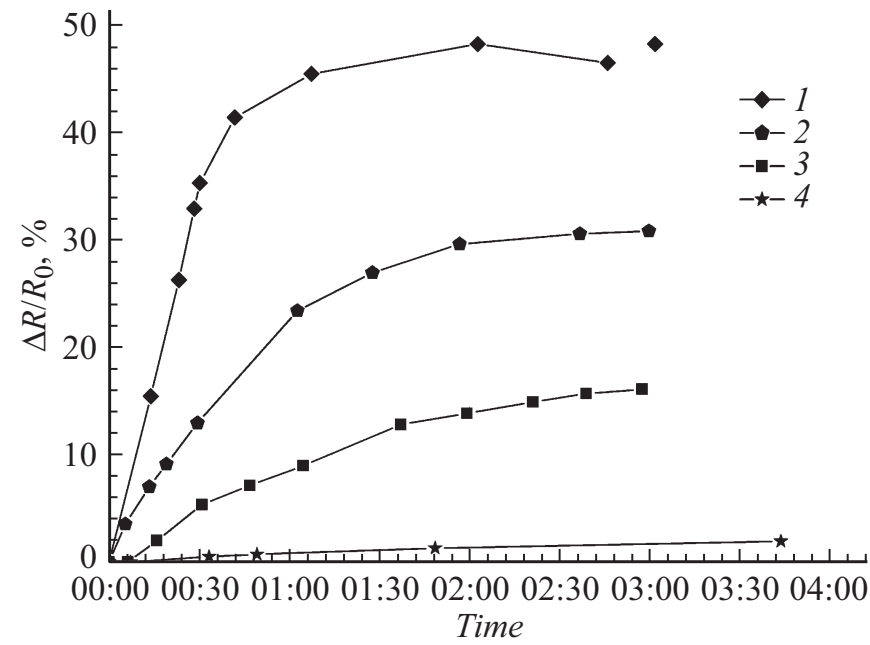

Рис. 3. Изменение относительного сопротивления спирали: 1 - совместная подача метана и водорода в канал со спиралью, 2 - подача метана в середину канала со спиралью, 3 раздельная подача, 4 - боковая подача метана.

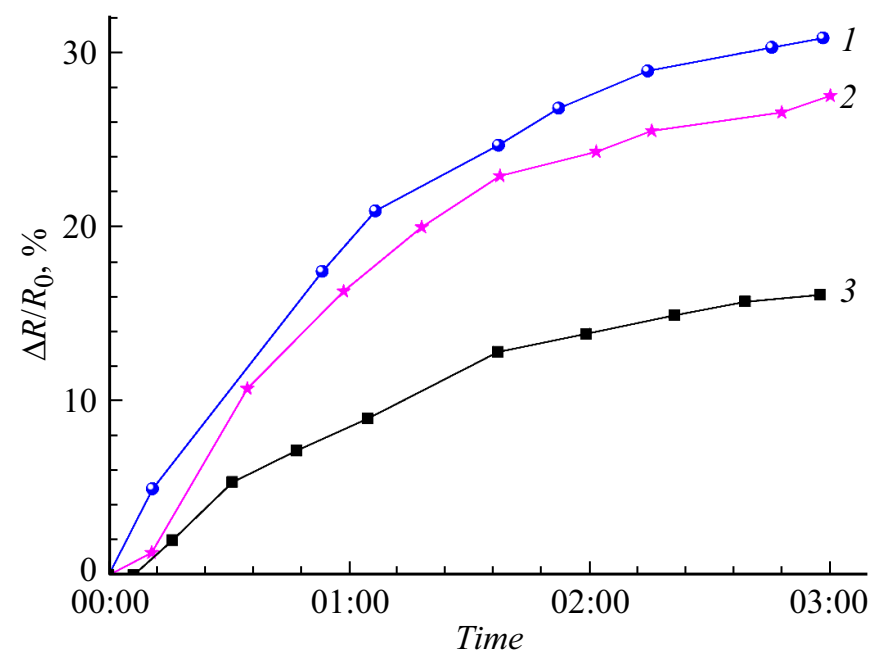

Рис. 4. Относительное сопротивление спирали в течение эксперимента с одним (1), двумя (2) и тремя (3) хомутиками.

покрытия с малым содержанием алмазных структур. Размер грани кристалла не удалось получить более $4 \mu \mathrm{m}[5,6]$. Науглероживание спирали удалось радикально снизить применением боковой подачи метана: в канал со спиралью подавался только водород, а газовая смесь $\mathrm{H}_{2}+\mathrm{CH}_{4}$ подавалась через боковой цилиндрический канал под углом к оси реактора $45^{\circ}$ в пространство между спиралью и подложкой [7]. В экспериментах с боковой подачей наблюдалось слабое изменение сопротивления спирали (кривая 4), что можно объяснить формированием лишь незначительного потока фрагментов метана из камеры в область нахождения спирали. В этом случае удалось получить крупные кристаллы алмаза с размером граней до $60 \mu \mathrm{m}$ [7]. Основным недостатком такого подхода была сложность систематического повторения результатов эксперимента вследствие чувствительности 


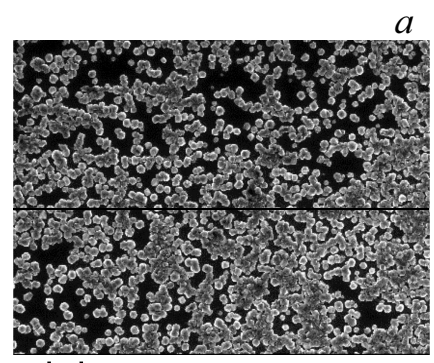

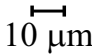

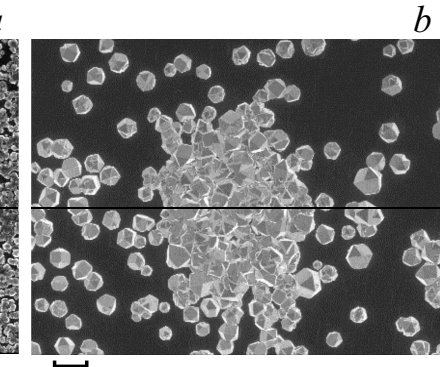

$10 \stackrel{\mathrm{m}}{\longmapsto}$

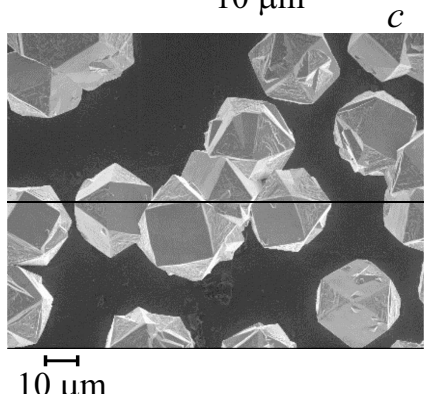

$10 \mu \mathrm{m}$

Рис. 5. Микрофотографии алмазных кристаллов в экспериментах с одним, двумя и тремя хомутиками.

процесса формирования алмазных структур к малейшим колебаниям положения и размеров боковой трубки. Идея раздельной подачи активированной метановой смеси в область осаждения получила развитие в аксиальносимметричной постановке, позволяющей получать более предсказуемые условия смешения активированных газовых потоков перед подложкой [6,8-11]. В этом случае решено использовать центральный канал для подачи смеси метана с водородом (рис. 1, трубка 4,5), а в кольцевой канал со спиралью подавать только водород. Смешение активированных газовых потоков из обоих каналов осуществлялось в области между срезами трубок и подложкой. К преимуществам этой схемы, кроме защиты спирали, можно отнести возможность управления параметрами режима разложения метана выбором температуры и давления в канале подачи $[6,11]$. Использование такой схемы позволило существенно снизить рост электрического сопротивления спирали (кривая 3) и получить в отдельных экспериментах кристаллы с размерами граней 15-20 $\mu \mathrm{m}$. Чтобы оценить степень влияния раздельной подачи на эффективность защиты спирали от науглероживания, был проведен тестовый эксперимент с подачей смеси через укороченную трубку 5 (рис. 1) в середину кольцевого канала. Измерение электрического сопротивления показало заметное снижение его роста в ходе эксперимента по отношению к совместной подаче (кривая 2), но рост происходил значительно быстрее, чем в схеме с боковой подачей. Полученные кристаллы имели размер граней 4-5 $\mu \mathrm{m}$. Проведенный анализ изменения сопротивления в процессе синтеза алмазных структур показал, что при большом его росте отмечается существенное ухудшение получаемого покрытия при прочих равных условиях проведения эксперимента. Также было замечено, что в ряде экспериментов при прочих равных условиях наблюдается существенное различие в изменении сопротивления, не поддающееся объяснению. Причина была найдена после обнаружения двух независимых каналов поступления метана к спирали: просачивания метана и его фрагментов в кольцевой канал через стенки трубки 5 (рис. 1) и заброс из камеры вследствие диффузии и отражения от подложки.

Стенки центрального канала 5 (рис. 1) выполнены из двух плотных слоев вольфрамовой фольги. При подаче смеси метана и водорода в такую трубку возможно просачивание метана и его фрагментов в кольцевой канал через межслоевой зазор. Количество проходящего газа из центрального канала в кольцевой канал в этом случае зависит от разности давлений в каналах и величины зазора. Разность давлений определяется расходами газов в каналах и их температурой. Уменьшение величины газопроницаемости через межслоевой зазор удалось добиться улучшением стягивания слоев фольги путем установки стягивающих хомутиков на трубку 5 (рис. 1). На рис. 4 представлены изменения электрического сопротивления спирали во времени при использовании трубки 5 (рис. 1), стенки которой имеют различную газопроницаемость. Из полученных данных следует, что наименьшее изменение сопротивления отмечается в эксперименте с тремя хомутиками. В этом случае газопроницаемость стенки минимальна, что заметно снижает поступление метана в водородный канал и снижает карбидизацию спирали.

На рис. 5 в качестве примера влияния науглероживания спирали на морфологию синтезируемых кристаллов приведены микрофотографии алмазных кристаллов, полученных в экспериментах с одним, двумя и тремя хомутиками. Из представленных данных видно,

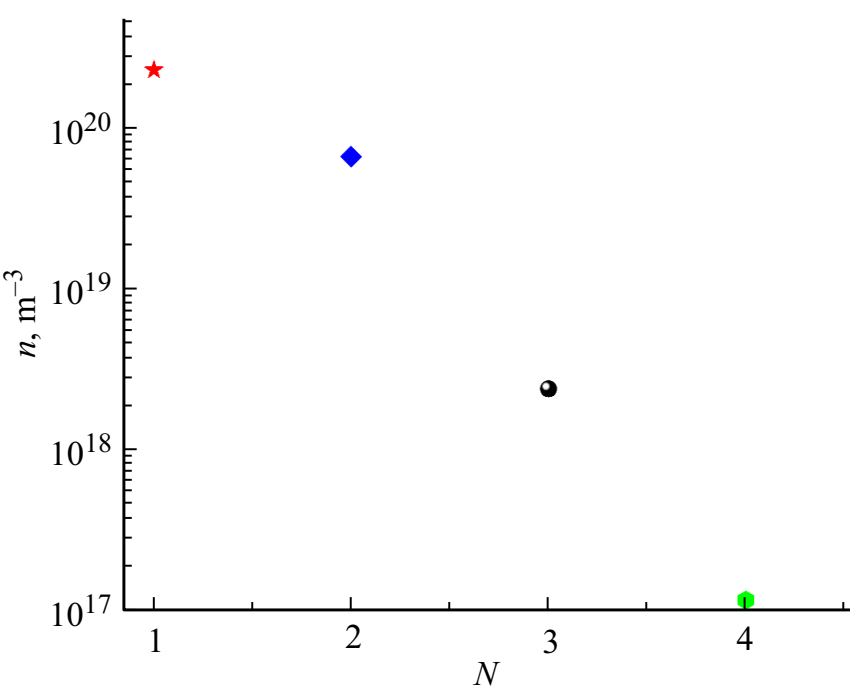

Рис. 6. Плотность метана вблизи первого кольца спирали для четырех численных экспериментов: $1-$ с подложкой для давления в камере $2666 \mathrm{~Pa} ; 2$ - без подложки для давления в камере $2666 \mathrm{~Pa} ; 3-$ с подложкой для давления в камере $266.6 \mathrm{~Pa} ; 4$ - без подложки для давления в камере $266.6 \mathrm{~Pa}$. 
что скорость роста кристаллов существенно возрастает, если обеспечить наименьшую газопроницаемость стенок центрального канала. В этих экспериментах средний размер грани алмазных кристаллов имел значения 2-3, 5-8 и $15-20 \mu \mathrm{m}$ соответственно.

Заброс метана и его фрагментов из камеры вследствие диффузии и отражения от подложки был понят из численных экспериментов. Расчеты показали формирование вихревого течения вследствие отражения потоков метана и водорода от подложки, приводящего к попаданию значительного количества метана в область спирали. Отметим, что истечение газа из кольцевого канала существенно дозвуковое (число Маха 0.1). На рис. 6 приведены данные по плотности метана вблизи первого кольца спирали (рис. $2-x=0.02 \mathrm{~m}$ ) для четырех численных экспериментов. Отсутствие подложки в расчете приводит к значительному снижению плотности метана, однако его величина остается значительной вследствие рассеивания метана на фоновом газе. Уменьшение фонового давления приводит к снижению заброса метана на порядок даже при наличии подложки.

Расчетам сопоставлен эксперимент. На рис. 7 представлено сравнение изменения сопротивления спирали без подложки (кривая 1) при подаче смеси в канал. В отсутствие подложки наблюдается замедленный рост электрического сопротивления, что, по-видимому, вызвано отсутствием отраженного потока от подложки. При отключении подачи метана происходит восстановление величины сопротивления до начального уровня (кривая 2), что может свидетельствовать об очистке спирали от углерода. Это согласуется с литературными данными [14-18]. Восстановленная спираль была использована для осаждения алмазных структур. Несмотря на значительный рост относительного электрического сопротивления в ходе эксперимента (до 25\%), было получено алмазное покрытие с размером кристаллов порядка $15 \mu \mathrm{m}$. Это является дополнительным свидетельством возможности восстановления каталитических

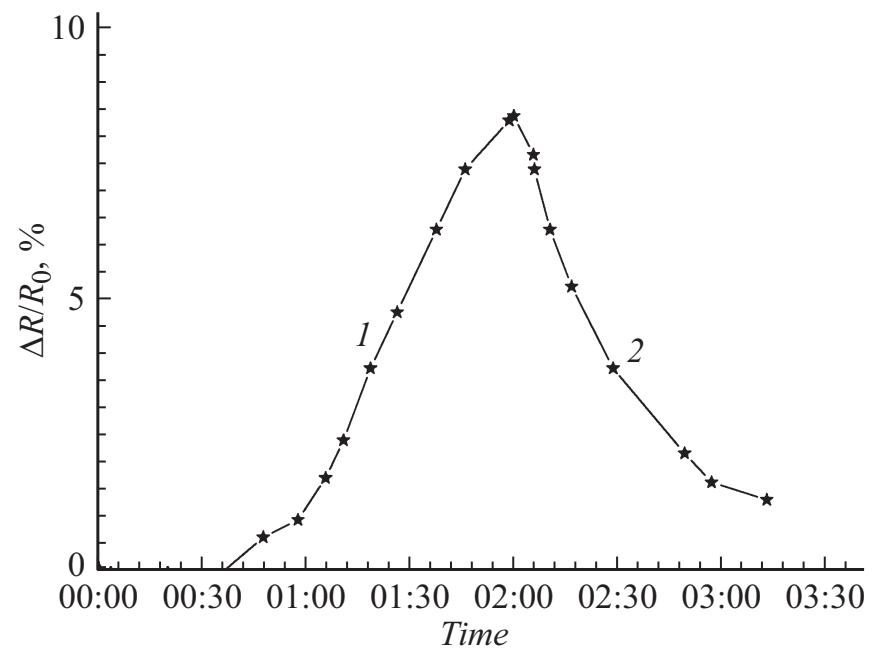

Рис. 7. Изменение относительного сопротивления спирали во времени при подаче газов в камеру без подложки.

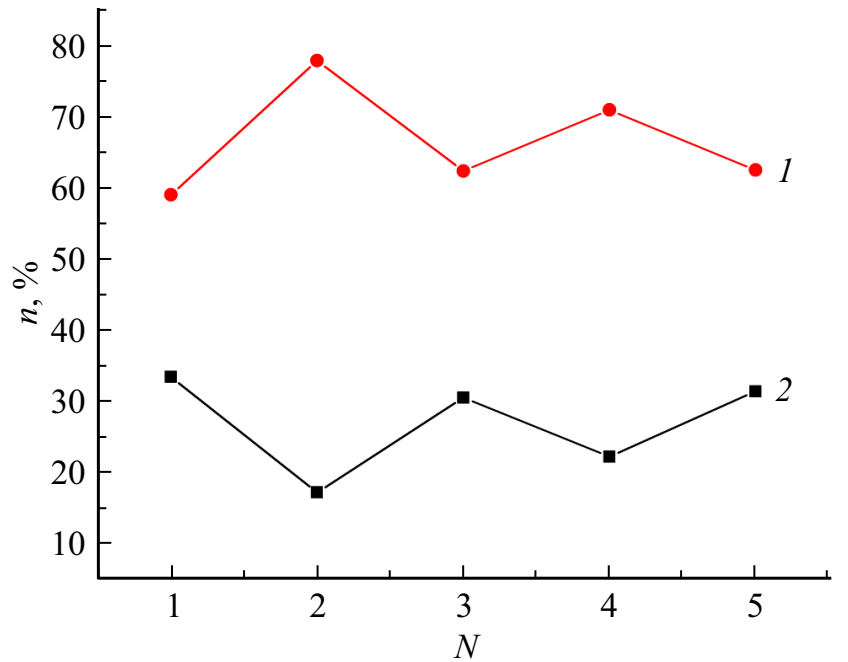

Рис. 8. Результаты элементного анализа поверхности витков спирали: 1 - углерод, 2 - вольфрам.

способностей спирали. Значительный рост относительного сопротивления в этом эксперименте, по-видимому, связан с температурной деформацией центрального канала при остывании после тестового эксперимента без подложки.

Элементный анализ витков поверхности спирали (рис. 8) после этого эксперимента по осаждению алмазных структур свидетельствует о равномерном науглероживании витков, вызванном проникновением метана в кольцевой канал через стенки трубки и из вакуумной камеры. Также был проведен элементный анализ внешней и внутренней поверхностей кольцевого канала 1 (рис. 1). Установлено, что покрытие углеродом внешней поверхности кольцевого канала составляет $\sim 30 \%$, внутренней поверхности - 70\%. Рост покрытия внутренней поверхности углеродом согласуется с имеющимися литературными данными, так как температура этой поверхности в ходе эксперимента была около $2100 \mathrm{~K}$.

\section{Заключение}

С целью развития газоструйного метода осаждения алмазных структур проведено исследование течения смеси водорода с метаном через коаксиальные нагретые вольфрамовые цилиндрические каналы со встроенной в них вольфрамовой спиралью. Вольфрамовая спираль использовалась как для нагрева реактора и подаваемых газов, так и для активации протекающего через кольцевой канал водорода. Основное внимание уделено исследованию науглероживания вольфрамовой спирали и влиянию науглероживания на скорость осаждения и морфологию алмазных покрытий. Контроль изменения науглероживания спирали осуществлялся измерением ее электрического сопротивления.

Экспериментально установлено существование двух независимых каналов поступления метана к спирали. 
При подаче смеси $\mathrm{H}_{2}+\mathrm{CH}_{4}$ в реактор в отсутствии подложки рост сопротивления спирали происходит в основном за счет просачивания метана в кольцевой канал через его стенки, а при наличии подложки происходит вихревое отражение газового потока, который дополнительно забрасывается в канал, и вследствие этого происходит ускорение науглероживания спирали. Проведенное прямое статистическое моделирование течения смеси через коаксиальные цилиндрические каналы со встроенной в них спиралью подтвердило вихревое отражение газового потока от подложки и от фонового газа в камере.

Экспериментально установлено, что значительный рост электрического сопротивления спирали в ходе эксперимента (при постоянной мощности источника питания) приводит к уменьшению скорости роста алмазных кристаллов. Оказалось, что если изменение относительного сопротивления составляет менее $20 \%$ за $3 \mathrm{~h}$, то результаты таких экспериментов можно сравнивать между собой и выявлять закономерности роста алмаза в зависимости от параметров эксперимента. В противном случае результаты сильно искажаются, по всей видимости, влиянием науглероженности спирали, и корректное сравнение проводить нельзя.

Полученные результаты и разработанные методики полезны для оптимизации газодинамических реакторов, используемых для осаждения алмазных структур.

\section{Благодарности}

Авторы благодарят академика РАН А.К. Реброва за полезные замечания при обсуждении работы.

\section{Финансирование работы}

Работа выполнена при частичной поддержке гранта Российского фонда фундаментальных исследований (проект № 18-08-00295) и бюджетных грантов AAAA-A17-117022850029-9 и AAAA-A17-117030110017-0.

\section{Конфликт интересов}

Авторы заявляют, что у них нет конфликта интересов.

\section{Список литературы}

[1] Спицын Б.В., Алексеенко А.А. // Защита металлов. 2007. T. 43. № 5. C. 456-474. DOI: $10.1134 / \mathrm{S} 0033173207050025$ [Spitsyn B.V., Alexenko A.E. // Protection of Metals. 2007. Vol. 43. N 5. P. 415-431.]

[2] Хмельницкий Р.А. // УФН. 2015. Т. 185. № 2. С. 143-159. DOI: 10.3367/UFNe.0185.201502b.0143 [Khmelnitskiy R.A. // Phys. Usp. 2015. Vol. 58. P. 134-149.]

[3] Ребров А.К. // УФН. 2017. Т. 187. № 2. С. 193-200. DOI: 10.3367/UFNe.2016.04.037794 [Rebrov A.K. // Phys. Usp. 2017. Vol. 60. N 2. P. 179-186.]
[4] May P.W. // Phil. Trans. R. Soc. Lond. A. 2000. Vol. 358. P. 473-495. DOI: $10.1098 /$ rsta.2000.0542

[5] Емельянов А.А., Ребров А.К., Юдин И.Б. // ПМТФ. 2014. T. 55. № 2. C. 94-100. DOI: 10.1134/S0021894414020096 [Emelyanov A.A., Rebrov A.K., Yudin I.B. // J. Appl. Mech. Tech. Phys. 2014. Vol. 55. N 2. P. 270-276.]

[6] Emelyanov A.A., Rebrov A.K., Yudin I.B. // Phys. Stat. Sol. A. 2014. Vol. 211. N 10. P. 2279-2283. DOI: $10.1002 /$ pssa.201431175

[7] Rebrov A., Emelyanov A., Kosolobov S., Yudin I. // Phys. Status Solidi C. 2015. Vol. 12, N 7. P. 931-933. DOI: $10.1002 /$ pssc. 201510043

[8] Rebrov A.K., Andreev M.N., Bieiadovskii T.T., Kubrak K.V. // Surf. Coat. Technol. 2017. Vol. 325. P. 210-218. DOI: $10.1016 /$ j.surfcoat.2017.06.060

[9] Емельянов А.А., Ребров А.К., Юдин И.Б. // ЖТФ. 2016. Т. 86. Вып. 12. C. 56-59. DOI: 10.1134/S1063784216120124 [Emel'yanov A.A., Rebrov A.K., Yudin I.B. // Tech. Phys. 2016. Vol. 61. N 12. P. 1821-1824.]

[10] Rebrov A. // Diam Relat Mater. 2017. Vol. 72. P. 20-25. DOI: $10.1016 /$ j.diamond.2016.12.014

[11] Ребров А.К., Емельянов А.А., Плотников М.Ю., Юдин И.Б. // ПМТФ. 2017. Т. 58. № 5 (345). С. 142-150. DOI: $10.1134 / \mathrm{S} 0021894417050145$ [Rebrov A.K. Emel'yanov A.A., Plotnikov M.Yu., Yudin I.B. // Appl. Mech. Tech. Phys. 2017. Vol. 58. N 5. P. 881-888.]

[12] Ребров А.К., Юдин И.Б. // ДАН. 2016. Т. 468. № 1. C. 33-36. DOI:10.1134/S1028335816050025 [Rebrov A.K., Yudin I.B. // Dokl. Phys. 2016. Vol. 61. N 5. P. 223-226.]

[13] Plotnikov M.Yu., Shkarupa E.V. // Vacuum. 2016. Vol. 129. P. 31-37. DOI: 10.1016/j. vacuum.2016.04.001

[14] Харатьян С.Л., Чатилян А.А., Мержсанов А.Г. // Химическая физика. 1987. T. 6. № 2. С. 225-233. [Kharatyan S.L., Chatilyan A.A., Merzhanov A.G. // Khim. Fiz. 1987. Vol. 6. N 2. P. 225-233.]

[15] Okoli S., Haubner R., Lux B. // Surf. Coat. Technol. 1991. Vol. 47. N 1-3. P. 585-599. DOI: $10.1016 / 0257-8972(91) 90329-\mathrm{U}$

[16] Boudart M., Ollis D.F., Harris G.W. // Trans. Faraday Soc. 1969. Vol. 65. P. 519-528.

[17] Sommer M., Smith F.W. // J. Mater. Res. 1990. Vol. 5. N 11 P. 2433-2440. DOI: 10.1557/JMR.1990.2433

[18] Winters H.F., Seki H., Rye R.R., Coltrin M.E. // J. Appl. Phys. 1994. Vol. 76. P. 1228-1243. DOI: 10.1063/1.357852

[19] Емельянов А.А., Юдин И.Б., Ребров А.К., Лебедев В.А. В сб. тезисов Всеросс. конф. XXXI „Сибирский теплофизический семинар“. 2014. Новосибирск. С. 202.

[20] Плотников М.Ю., Шкарупа Е.В. // ПМТФ. 2017. Т. 58. N 3 (343). C. $30-38$. DOI: 10.1134/S002189441703004X [Plotnikov M.Yu., Shkarupa E.V. // Appl. Mech. Tech. Phys. 2017. Vol. 58. N 3. P. 402-409.]

[21] Koschmieder H., Raible V. // Rev. Sci. Instrum. 1975. Vol. 46. P. 536-537. DOI: 10.1063/1.1134251

[22] Ivanov M.S., Rogasinsky S.V. // Russ. J. Numer. Anal. Math. Modelling. 1988. Vol. 3. N 6. P. 453-466. DOI: 10.1515/rnam.1988.3.6.453

[23] Bird G.A. Molecular gas dynamics and the direct simulation of gas flows. Oxford: Clarendon Press, 1994.

[24] Morozov A.A., Plotnikov M.Yu., Rebrov A.K., Yudin I.B. In Proc. of $30^{\text {th }}$ Intern. Symp. on Rarefied Gas Dynamics. Canada. 2016. NY.: AIP Conf. Proc. 2016. Vol. 1786. P. 050015. DOI: $10.1063 / 1.4967565$ 